\title{
Levetiracetam and lamotrigine effects as mono- and polytherapy on bone mineral density in epileptic patients
}

\author{
Efeitos do levetiracetam e lamotrigina, em mono e politerapia, na densidade mineral \\ óssea de pacientes epilépticos
}

Sahar Mohamed El-Haggar¹, Tarek Mohamed Mostafa¹, Horeya Mohamed Sad Allah², Ghada Hassan Akef

\begin{abstract}
The purpose of this study was to determine the effect of lamotrigine (LTG) and levetiracetam (LEV) as mono- and polytherapy on biochemical markers of bone turnover and bone mineral density in Egyptian adult patients with epilepsy. Methods: Forty-eight patients were divided into four groups: two received monotherapy of either LTG or LEV, and the other two groups received polytherapy comprising (valproate [VPA] + LTG or VPA + LEV). Thirty matched healthy participants were included in the study. Participants completed a nutritional and physical activity questionnaire. Biochemical markers of bone and mineral metabolism and bone mineral density of the lumbar spine were measured at baseline and at six months. Results: In the LEV monotherapy group, the bone formation markers showed a significant decrease in serum alkaline phosphatase and serum osteocalcin levels while the bone resorption marker showed a significant increase in urinary deoxypyridinoline levels. After six months of treatment, bone mineral density showed a significant decrease in all treated groups, while among monotherapy groups, this significant decrease was more prevalent in the LEV monotherapy group compared with the LTG monotherapy group. Furthermore, there was significant negative correlation between urinary deoxypyridinoline levels and bone mineral density in the LEV monotherapy group. Conclusion: Using new generation antiepileptics, LEV monotherapies and polytherapy showed harmful effects on bone but LTG did not.
\end{abstract}

Keywords: bone density; epilepsy.

\section{RESUMO}

O objetivo deste estudo foi determinar o efeito da lamotrigina (LTG) e levetiracetam (LEV) como mono e politerapia em marcadores bioquímicos de remodelação óssea e densidade mineral óssea em pacientes adultos egípcios com epilepsia. Métodos: Quarenta e oito pacientes foram divididos em quatro grupos: dois grupos receberam monoterapia de LTG ou LEV e os outros dois grupos receberam politerapia (valproato [VPA] + LTG ou VPA + LEV). Trinta participantes saudáveis controle foram incluídos no estudo. Os participantes preencheram um questionário nutricional e de atividade física. Marcadores bioquímicos do metabolismo ósseo e mineral e densidade mineral óssea da coluna lombar foram medidos no início e aos seis meses. Resultados: No grupo de monoterapia LEV, os marcadores de formação óssea mostraram uma diminuição significativa nos níveis séricos de fosfatase alcalina e osteocalcina sérica, enquanto o marcador de reabsorção óssea mostrou um aumento significativo nos níveis de desoxipiridinolina urinária. Após seis meses de tratamento, a densidade mineral óssea mostrou uma diminuição significativa em todos os grupos tratados, enquanto entre os grupos de monoterapia, esta diminuição significativa foi mais prevalente no grupo de monoterapia LEV em comparação com o grupo de monoterapia LTG. Além disso, houve correlação negativa significativa entre os níveis de desoxipiridinolina urinária e densidade mineral óssea no grupo de monoterapia LEV. Conclusão: Utilizando antiepilépticos de nova geração, as monoterapias LEV e a politerapia mostraram efeitos prejudiciais no osso, mas a LTG não.

Palavras-chave: densidade óssea; epilepsia.

Neurologic disorders are the most prevalent genetic disorders in Egypt, accounting for $31.38 \%$ of all genetic disorders $^{1}$. Epilepsy is a neurological disorder that requires lifelong treatment. Unfortunately, the treatment usually affects both bone and mineral metabolism and may increase the risk of fractures ${ }^{2}$.

Many studies have found a link between antiepileptic drugs (AEDs) and bone disease ${ }^{3}$. Old AEDs, such as

\footnotetext{
${ }^{1}$ Tanta University, Faculty of Pharmacy, Department of Clinical Pharmacy, Egypt;

${ }^{2}$ Alexandria University, Faculty of Medicine, Department of Neuropsychiatry, Egypt;

${ }^{3}$ Alexandria University, Faculty of Pharmacy, Egypt.

Correspondence: Ghada Hassan Akef; 127Alexander the great ST., El-Chatby, Alexandria, Egypt 21526; E-mail: ghadaakef@yahoo.com

Conflict of interest: There is no conflict of interest to declare.

Received 12 January 2018; Received in final form 23 March 2018; Accepted 19 April 2018.
} 
phenobarbital and phenytoin-induced hepatic (CYP-450) enzymes, led to an increase of catabolism of vitamin $\mathrm{D}$, and this subsequently decreased the absorption of calcium ${ }^{4}$. However, this proposed mechanism has failed to explain the same condition reported in patients receiving valproate (VPA), an inhibitor of the CYP-450 enzyme ${ }^{5}$.

Bone remodeling is a lifelong process in which the skeleton is continuously being resorbed and replaced to maintain skeletal integrity. Serum markers of bone formation are bone-specific alkaline phosphatase, osteocalcin and carboxy-terminal propeptide of type I procollagen. Markers of bone resorption are serum carboxy-terminal telopeptide of type 1 collagen, urinary $\mathrm{N}$-telopeptide of type 1 collagen bone and hydroxypyridinium cross-links collagen (pyridinoline and deoxypyridinoline) $)^{6}$.

Serum osteocalcin is a specific marker of osteoblast function, as its levels correlate with the bone formation rate. The major advantages of using osteocalcin are its tissue specificity, its wide availability, and its relatively low withinperson variation ${ }^{7}$.

The hydroxypyridinium cross-links collagen, deoxypyridinoline, is formed during the extracellular maturation of collagens and released upon the degradation of mature collagens. Its major advantages are that its measurement dose is not influenced by degradation of newlysynthesized collagens and is independent of dietary sources. Deoxypyridinoline is found only in bone and dentin and may be derived from the cancellous and cortical compartments of bone. The presence of deoxypyridinoline in urine can be regarded as a specific marker of bone turnover ${ }^{8}$.

New generations of AEDs such as lamotrigine (LTG), topiramate and levetiracetam (LEV) are approved to be used as antiepileptic monotherapy or adjuvant therapy9. Few studies have investigated the adverse effects of new AEDs on bone mineral density and bone turnover. Some of these studies demonstrated a negative influence of these drugs on bone health status, and other studies have shown contradictory effects ${ }^{10,11}$.

These previously-reported conflicting findings warrant further studies to evaluate the possible adverse effects of novel antiepileptic drugs on bone health. In this context, our study aimed to evaluate and compare the effects of old and new generations of monotherapy AEDs on both biochemical markers of bone turnover and on bone mineral density in Egyptian adult patients with epilepsy.

\section{METHODS}

\section{Participants}

In this case-control study, 68 adult patients with a recently-diagnosed epilepsy were recruited from the Epilepsy Clinic of the Neuropsychiatric Department, Alexandria Main University Hospital, Alexandria, Egypt between January 2013 and November 2016. The diagnosis of epilepsy was made in accordance with the criteria of the International League Against Epilepsy. The patients had different generalized tonic-clonic, myoclonic and absence seizure types. Exclusion criteria were mental retardation, postmenopausal women, immobilization, diseases that affect the skeleton (Paget disease, multiple myeloma), and those taking glucocorticoids and excessive doses of vitamins. The ethical committee of Alexandria University approved the study. A written informed consent for participation was obtained from each patient or his/her legal representative.

Thirty healthy subjects were included as a control group, and their selection criteria matched the patients' age, gender, body mass index, and social economic state. The recruited participants periodically visited the Alexandria Regional Centre for Health and Development for checkups.

Of the 68 patients, 20 were excluded for the following reasons: patients had to change to a different AED $(n=5)$; patients moved and were lost to follow-up $(n=6)$; patients got pregnant $(\mathrm{n}=5)$; and patients with coincidental endocrinological diseases $(n=4)$.

Eventually, 30 healthy subjects and 48 patients were included in this study. Each patient in this study underwent a full medical examination and family history, including menarchal age and reproductive history. Patients were treated with mono- and polytherapy AEDs (with doses within therapeutic range) including VPA (Depakine $500 \mathrm{mg}$ tablets, Sanofi Aventis, Berlin, Germany), LTG (Larogen 100 mg tablets, Delta Pharm, Egypt) and LEV (Tiratam $500 \mathrm{mg}$ tablets, Al Andalous Egypt). During the six month follow-up period, patients visited the epilepsy clinic monthly for follow-up and dispensing of their AEDs, and this information was recorded on their dispensing card.

\section{Study design}

Each participant completed a validated nutritional and physical activity questionnaire. The nutrition questionnaire is a food frequency questionnaire that assesses daily diet, meals and snacks, vitamin intake, tobacco, and alcohol ${ }^{12}$. The physical activity questionnaire evaluates the duration and frequency of specific exercises and daily activities ${ }^{13}$. Patients were instructed to maintain the same dietary habits and level of physical activity during the study period.

Fasting blood and urine samples were collected for measurement of biochemical bone mineral parameters. All samples were coded and stored at -15 to $-25{ }^{\circ} \mathrm{C}$ until use. Serum calcium, phosphate and alkaline phosphatase were measured using the available colorimetric method (Roche/ Hitachi cobas (c 501) analyzers; Germany). Serum parathyroid hormone and osteocalcin were measured with the ElectroChemiLuminescence Immuno Assay kit (Elecsys and cobas (e 411) analyzers; Roche, Germany). Markers of bone resorption urinary deoxypyridinoline were measured by the Enzyme Immunoassay EIA kit (Quidel MicroVue 
DPD-Enzyme Immunoassay; Hannover, Germany). The results of urinary markers were expressed in relation to urinary creatinine. Bone mineral density of the lumbar spine, which consists mainly of trabecular bone and is a common site of compression fracture, was measured using a dual energy X-ray absorptiometry scanner (DEXA, QDR4500A, Hologic, Waltham, MA) at the Alexandria Regional Centre for Women's Health and Development. Bone mineral density was assessed according to the World Health Organization guideline that defined osteoporosis as a T-score less than -2.5 at any site and osteopenia as a T-score between -1 and -2.5. All tests were measured at baseline and after six months ${ }^{14,15}$.

The follow-up period in this study was six months and this duration accounted for two bone remodeling cycles considering that each cycle is approximately three months. This period was chosen to ensure that the effects of prior AED exposure would have been unlikely to influence bone turnover markers and rates of bone loss ${ }^{14,15}$.

\section{Tests of measurement}

Serum calcium levels were measured photometrically using the cobas c 501 analyzer (Roche/Hitachi, Germany). Test principle: calcium ions react with 5-nitro-5.-methylBAPTA under alkaline conditions to form a complex. This complex reacts in the second step with EDTA. The change in absorbance is directly proportional to the calcium concentration in the sample.

Serum phosphate levels were measured photometrically using the cobas c 501 analyzer (Roche/Hitachi, Germany). Test principle: the phosphate concentration was measured spectrophotometrically. Phosphate forms an ammonium phosphomolybdate complex with ammonium molybdate in the presence of sulfuric acid. The concentration of phosphomolybdate formed is directly proportional to the phosphate concentration in the provided samples.

Serum alkaline phosphatase levels were measured photometrically using the cobas c 501 analyzer (Roche/ Hitachi, Germany). Test principle: in the presence of magnesium and zinc ions, $\rho$-nitrophenyl phosphate is cleaved by alkaline phosphatase into phosphate and $\rho$-nitrophenol. The $\rho$-nitrophenol released results in an increase of absorbance, which is directly proportional to the catalytic alkaline phosphatase activity.

Serum parathyroid hormone and osteocalcin were measured by the ElectroChemiLuminescence Immune Assay. Test principle: the sandwich technique.

First incubation of serum parathyroid hormone: $50 \mu \mathrm{l}$ of sample, a biotinylated monoclonal parathyroid hormone-specific antibody, and monoclonal parathyroid hormone-specific antibody labeled with a ruthenium complex form a sandwich complex.

First incubation of serum osteocalcin: $20 \mu \mathrm{l}$ of sample, a

biotinylated monoclonal N-MID osteocalcin-specific antibody, and monoclonal N-MID osteocalcin-specific antibody labeled with a ruthenium complex form a sandwich complex.

Second incubation parathyroid hormone and osteocalcin: after addition of streptavidin-coated microparticles, the complex becomes bound to the solid phase via interaction of biotin and streptavidin. The reaction mixture is aspirated into the measuring cell where the microparticles are magnetically captured onto the surface of the electrode. Unbound substances are then removed with Pro Cell/ Clean Cell. Application of a voltage to the electrode then induces chemiluminescent emission, which is measured by a photomultiplier.

Urinary deoxypyridinoline was measured by enzyme immunoassay using the Quidel MicroVue DPD-Enzyme Immunoassay Kit 30175 (Hannover, Germany). The urinary deoxypyridinoline assay is a competitive enzyme immunoassay in a microtiter stripwell format utilizing a monoclonal anti-deoxypyridinoline antibody coated on the strip to capture deoxypyridinoline. Deoxypyridinoline in the sample competes with conjugated deoxypyridinoline-alkaline phosphatase for the antibody and the reaction is detected with a $\rho$-nitrophenyl phosphate substrate. The deoxypyridinoline results are corrected for urinary concentration by creatinine using the formula; deoxypyridinoline = deoxypyridinoline / urinary creatinine $\mathrm{x} 0.088$

Urinary creatinine was measured photometrically using the Roche/Hitachi cobas c 501 analyzer. The test principle was based on the conversion of creatinine with the aid of creatininase to creatine. This creatine, with the action of creatinase, is converted to sarcosine. The sarcosine, through the action of sarcosine oxidase, is convert to glycine, formaldehyde and hydrogen peroxide. This liberated hydrogen peroxide is catalyzed by peroxidase and then reacts with 4-aminophenazone and 2,4,6-triiodo-3-hydroxybenzoic acid to form a quinoneimine chromogen. The color of the quinoneimine chromogen formed is directly proportional to the creatinine concentration in the samples.

\section{RESULTS}

Of the 48 patients aged between 18-42 years who completed the six-month follow-up period, the mean age was $21.33 \pm 3.03$; there were not significantly more females than males; and the generalized tonic-clonic type was the more prevalent seizure type. Dietary intake of calcium, exposure to sunlight hours, amount of exercise, age of menarche and number of pregnancies did not differ among groups (Table 1).

The mean dose and serum drug levels were found to be in therapeutic range for all AEDs studied. Group 1 comprised patients taking monotherapy LTG $191.67 \pm 79.3 \mathrm{mg} /$ day, and Group 2 comprised patients taking monotherapy LEV 1,250 
Table 1. Demographic data and biochemical parameters for all participants at baseline.

\begin{tabular}{|c|c|c|c|c|c|c|}
\hline Characteristics & Healthy & LTG & LEV & VPA+LTG & VPA + LEV & $p$ \\
\hline Age (mean \pm SD) & $21.33 \pm 3.03$ & $19.92 \pm 2.43$ & $20.17 \pm 2.72$ & $21.00 \pm 2.83$ & $20.67 \pm 2.87$ & 0.421 \\
\hline \multicolumn{7}{|l|}{ Sex } \\
\hline Male (n, \%) & $10(33.3 \%)$ & $2(16.7 \%)$ & $6(50.0 \%)$ & $4(33.3 \%)$ & $6(50.0 \%)$ & 0.105 \\
\hline Female $(n, \%)$ & $20(66.7 \%)$ & $10(83.3 \%)$ & $6(50.0 \%)$ & $8(66.7 \%)$ & $6(50.0 \%)$ & \\
\hline \multicolumn{7}{|l|}{ Seizure type } \\
\hline $\operatorname{GTC}(n, \%)$ & - & $6(50.0 \%)$ & $7(58.3 \%)$ & $8(66.7 \%)$ & $8(66.7 \%)$ & 0.336 \\
\hline Myoclonic (n, \%) & - & $3(25.0 \%)$ & $3(25.0 \%)$ & $3(25.0 \%)$ & $3(25.0 \%)$ & \\
\hline Absence (n, \%) & - & $3(25.0 \%)$ & $2(16.7 \%)$ & $1(8.3 \%)$ & $1(8.3 \%)$ & \\
\hline \multicolumn{7}{|l|}{ Questionnaire } \\
\hline Dietary calcium, mg/day & $1,032 \pm 0.11$ & $1,258 \pm 0.20$ & $1,095 \pm 0.20$ & $989 \pm 0.76$ & $1,105 \pm 0.18$ & 0.581 \\
\hline Exposure to sunlight (hr) & $1.28 \pm 0.40$ & $1.09 \pm 0.42$ & $1.45 \pm 0.53$ & $1.28 \pm 0.66$ & $1.17 \pm 0.68$ & 0.352 \\
\hline Physical activity (hr) & $3.36 \pm 14.21$ & $3.45 \pm 12.86$ & $2.18 \pm 15.01$ & $2.91 \pm 12.42$ & $3.16 \pm 16.27$ & 0.216 \\
\hline No. of pregnancies & $1.57 \pm 0.47$ & $1.82 \pm 0.69$ & $1.91 \pm 13.70$ & $1.55 \pm 0.36$ & $1.27 \pm 0.45$ & 0.221 \\
\hline Age of menarche & $13.00 \pm 0.11$ & $12.00 \pm 0.21$ & $12.00 \pm 0.31$ & $13.00 \pm 0.81$ & $12.00 \pm 0.21$ & 0.242 \\
\hline \multicolumn{7}{|l|}{ Bone parameters } \\
\hline Ca mg/dl & $4.93 \pm 0.11$ & $4.95 \pm 0.20$ & $4.87 \pm 0.20$ & $4.83 \pm 0.17$ & $4.88 \pm 0.18$ & 0.233 \\
\hline $\mathrm{PO}_{4} \mathrm{mg} / \mathrm{dl}$ & $3.96 \pm 0.40$ & $4.58 \pm 0.42$ & $4.45 \pm 0.53$ & $4.28 \pm 0.66$ & $4.17 \pm 0.68$ & 0.352 \\
\hline ALP U/L & $56 \pm 14.21$ & $50.18 \pm 13.93$ & $61.55 \pm 8.08$ & $45.91 \pm 12.42$ & $55.36 \pm 16.27$ & 0.216 \\
\hline PTH pg/ml & $47.57 \pm 8.47$ & $46.82 \pm 7.69$ & $43.91 \pm 13.70$ & $46.55 \pm 11.36$ & $45.27 \pm 8.45$ & 0.221 \\
\hline $\mathrm{OC} \mathrm{ng} / \mathrm{ml}$ & $20.50 \pm 5.11$ & $24.09 \pm 5.17$ & $31.45 \pm 2.21$ & $21.73 \pm 6.69$ & $21.68 \pm 6.52$ & 0.262 \\
\hline U.DPD, $\mathrm{nmol} / \mathrm{mmol}$ & $5.68 \pm 0.94$ & $6.30 \pm 0.57$ & $6.31 \pm 0.74$ & $6.35 \pm 0.73$ & $6.25 \pm 0.75$ & 0.356 \\
\hline BMD (T-score) & $-0.49 \pm 0.48$ & $-0.51 \pm 0.98$ & $-0.49 \pm 1.07$ & $-0.45 \pm 0.21$ & $-0.53 \pm 0.11$ & 0.326 \\
\hline
\end{tabular}

GTC: generalized tonic-clonic seizure; hr: hours;VPA: valproate; LTG: Lamotrigine; LEV: Levetiracetam; Ca: calcium; PO4; Phosphate; ALP: alkaline phosphatase; PTH: parathyroid hormone; OC: osteocalcin; U.DPD: urinary deoxypyridinoline; BMD: bone mineral density; SD: standard deviation. Data are expressed by mean \pm standard deviation; Level of significance was set at $p$-value $<0.05$.

$\pm 452.3 \mathrm{mg} /$ day. Group 3 comprised patients who were being treated with polytherapy VPA $1,125 \pm 226.13 \mathrm{mg} /$ day and LTG $316.67 \pm 83.5 \mathrm{mg} /$ day. Group 4 comprised patients who were being treated with polytherapy VPA and 1,250 $\pm 452.3 \mathrm{mg} /$ day and LEV $758.3 \pm 334.2 \mathrm{mg} /$ day.

\section{Bone mineral density and biochemical markers of bone and mineral metabolism}

The statistical analyses revealed that there were no significant differences between all groups at the baseline. The healthy participants group showed no significant differences before and after six months.

Regarding the biochemical parameters, as shown in Table 2, after six months of treatment there was a significant decrease in serum calcium concentrations in all treated groups with no significant change in phosphate and parathyroid hormone parameters. Serum calcium was decreased significantly more in subjects receiving VPA+LEV polytherapy than in those receiving VPA+LTG polytherapy $(\mathrm{p}=0.04)$.

We noted changes in bone turnover markers between the monotherapy groups. In patients in the LEV monotherapy group, we found a significant decrease in the bone formation markers (serum alkaline phosphatase and serum osteocalcin levels) while the bone resorption marker showed no significant change in urinary deoxypyridinoline levels. However, in patients in the LTG monotherapy group, we found no significant changes in bone turnover markers. On the other hand, both polytherapy groups showed significant increase in the bone formation markers (serum alkaline phosphatase and serum osteocalcin levels) and the bone resorption marker (urinary deoxypyridinoline levels).

Bone mineral density (T-score) after six months of treatment revealed a significant decrease in all treated groups except for the LTG monotherapy group. The significant decrease between monotherapy groups was more prevalent in the LEV monotherapy group when compared with the LTG monotherapy group $(p=0.036)$. No significant difference was shown between the LEV monotherapy group and the VPA+LEV polytherapy group.

To assess relationships between the bone mineral density and markers of bone turnover, Pearson's correlation coefficients were performed (Table 3). No significant relationships were detected in all the studied groups, except for a positive significant correlation between urinary deoxypyridinoline level and bone mineral density (T-score) in the LEV monotherapy group. 
Table 2. Changes in bone biochemical parameters and bone turnover markers in all treatment groups.

\begin{tabular}{|c|c|c|c|c|c|c|c|c|}
\hline \multirow{2}{*}{$\begin{array}{l}\text { Parameters/ } \\
\text { Groups }\end{array}$} & \multicolumn{2}{|c|}{ LTG $n=12$} & \multicolumn{2}{|c|}{ LEV $\mathrm{n}=12$} & \multicolumn{2}{|c|}{ VPA + LTG $n=12$} & \multicolumn{2}{|c|}{ VPA + LEV $n=12$} \\
\hline & Baseline & 6 months & Baseline & 6 months & Baseline & 6 months & Baseline & 6 months \\
\hline Ca mg/dl & $4.95 \pm 0.20$ & $4.50 \pm 0.08^{\star}$ & $4.87 \pm 0.20$ & $4.30 \pm 0.19 *$ & $4.83 \pm 0.17$ & $4.46 \pm 0.11^{\star}$ & $4.88 \pm 0.18$ & $3.89 \pm 0.27 * b$ \\
\hline $\mathrm{PO}_{4} \mathrm{mg} / \mathrm{dl}$ & $4.58 \pm 0.42$ & $4.40 \pm 0.59$ & $4.45 \pm 0.53$ & $4.05 \pm 0.75$ & $4.28 \pm 0.66$ & $4.11 \pm 0.60$ & $4.17 \pm 0.68$ & $4.07 \pm 0.64$ \\
\hline ALP U/L & $50.18 \pm 13.93$ & $47.45 \pm 12.86$ & $61.55 \pm 8.08$ & $45.18 \pm 15.0 *$ & $45.91 \pm 12.42$ & $62.45 \pm 14.91^{\star d}$ & $55.36 \pm 16.27$ & $70.64 \pm 18.56^{\star c}$ \\
\hline PTH pg/ml & $46.82 \pm 7.69$ & $52.55 \pm 8.63$ & $43.91 \pm 13.70$ & $46.36 \pm 6.04$ & $46.55 \pm 11.36$ & $48.36 \pm 5.57$ & $45.27 \pm 8.45$ & $47.82 \pm 4.51$ \\
\hline $\mathrm{OC} \mathrm{ng} / \mathrm{ml}$ & $24.09 \pm 5.17$ & $21.09 \pm 3.14$ & $31.45 \pm 2.21$ & $21.71 \pm 5.19 *$ & $21.73 \pm 6.69$ & $43.36 \pm 7.59 * d$ & $21.68 \pm 6.52$ & $42.00 \pm 8.12^{\star c}$ \\
\hline $\begin{array}{l}\text { U.DPD nmol/ } \\
\mathrm{mmol}\end{array}$ & 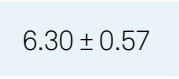 & 0.12 & ( & 6.6 & 6. & 8 & 6.25 & $8 * c$ \\
\hline BMD (T-score) & $-0.51 \pm 0.98$ & $-0.46 \pm 0.31$ & $-0.49 \pm 1.07$ & $-0.19 \pm 0.30$ *a & $-0.45 \pm 0.21$ & $-0.09 \pm 0.65^{\star d}$ & $-0.53 \pm 0.11$ & $-0.12 \pm 0.42^{\star}$ \\
\hline
\end{tabular}

VPA:valproate; LTG:Lamotrigine; LEV: levetiracetam;Ca:calcium; $\mathrm{PO}_{4}$ : phosphate;ALP: alkaline phosphatase; PTH: parathyroid hormone;OC: osteocalcin; U.DPD: urinary deoxypyridinoline; BMD: bone mineral density; SD: standard deviation. Data are expressed as mean \pm standard deviation. Level of significance was set at p-value $<0.05 .{ }^{*}$ Within- drug group change from baseline (paired t-test). ${ }^{a}$ Comparing LTG with LEV monotherapy groups after 6 months of treatment; ${ }^{\circ}$ Comparison between (VPA+LTG and VPA+LEV) polytherapy groups after 6 months of treatment; 'Comparing LEV with (VPA+LEV) treated groups after 6 months

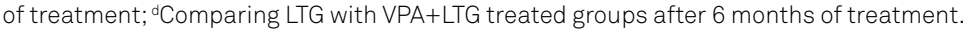

Table 3. Correlation between bone mineral density (T-score) and bone turnover markers in all studied groups.

\begin{tabular}{lccccc}
\hline \multirow{2}{*}{ Parameter } & \multicolumn{2}{c}{ LTG } & & \multicolumn{2}{c}{ LEV } \\
\cline { 2 - 3 } \cline { 5 - 6 } & $r$ & $p$ & & $r$ & $p$ \\
\hline Serum OC & 0.380 & 0.224 & & 0.320 & 0.312 \\
Urinary DPD & 0.391 & 0.209 & & 0.197 & $0.04^{*}$ \\
\hline
\end{tabular}

OC: osteocalcin (bone formation marker); U.DPD: urinary deoxypyridinoline (bone resorption marker); LTG: lamotrigine; LEV: levetiracetam; r: Pearson's correlation coefficient. Level of significance was set at $p$-value $<0.05$.

\section{DISCUSSION}

In the present study, patients on LEV monotherapy showed a significant decrease in bone mineral density and levels of bone formation markers (alkaline phosphatase, osteocalcin). The urine level of the bone resorption marker, urinary deoxypyridinoline, was not significantly changed.

Beniczky et al. ${ }^{16}$, in 2012, studied antiepileptic monotherapies: VPA, carbamazepine, LTG, oxcarbazepine, topiramate and LEV. They postulated that there was a significant reduction of bone mineral density in LEV monotherapy-treated patients. In a preclinical study in 2013, Fekete et al. ${ }^{17}$ demonstrated a significant loss of femoral bone marrow density following LEV therapy and a decrease of osteoprotegerin serum levels (a marker of bone formation) with significant elevation of C-terminal telopeptide of collagen type I (a marker of bone resorption). In 2007, in a preclinical study, Nissen-Meyer et al. ${ }^{11}$ demonstrated that LEV provoked a negative effect on bone marrow density.

In contrast to the previous studies, Anwar et al. ${ }^{18}$ in 2014, compared the effects of three AEDs; phenytoin, VPA, and LEV on the lumbar vertebrae of a Swiss strain of albino female mice and found that LEV did not provoke any significant alterations in bone mineral density. As well, Lee et al. ${ }^{19}$ in a 2012 clinical retrospective study, reported the absence of a deleterious effect of newer AEDs including LEV on bone mineral density.

It should be noted that the range of daily doses of LEV and treatment duration were different from the doses used in humans. These factors may explain the heterogeneity of results between preclinical and human studies.

The underlying mechanisms through which LEV can affect bone remodeling is still unclear. Levetiracetam might change the bone marrow density through disturbances in the bone tissue maturation that concerns suboptimal mineralization of cartilage, secondary to its direct negative effect on chondroclasts $^{20}$. Nissen-Meyer et al. ${ }^{11}$, in 2007, showed that LEV provoked a harmful effect on trabecular bones, which contain more cartilage content than cortical bone.

Recently, several case reports have shown that LEV was found to be associated with pancytopenia (bone marrow suppression) in epileptic patients ${ }^{21,22,23,24}$. In another report, LEV induced hyponatremia and thrombocytopenia ${ }^{25,26}$. The previously-mentioned information provides a logical justification for our result, which showed a positive relationship between bone marrow density and bone resorption marker urinary deoxypyridinoline using Pearson's correlation coefficient.

In the current study, patients on LTG monotherapy showed no change in their bone mineral density and only showed a significant reduction in calcium serum levels. This currently seems to be in agreement with the results obtained by Kim Lee et al. ${ }^{27}$ in 2007. In their prospective study of eight newly-diagnosed epileptic patients, the authors reported that LTG monotherapy for a six-month duration resulted in no abnormalities in bone mineral density, calcium, phosphate, vitamin $\mathrm{D}$ and urinary deoxypyridinoline levels. Furthermore, it has been demonstrated that LTG monotherapy showed a nonsignificant effect on bone turnover and on the indices of mineral metabolism, markers of bone formation and bone resorption in premenopausal epileptic women who were stabilized on LTG monotherapy for one year ${ }^{28,29,30}$. These aforementioned data may partially justify the results obtained in our study. In general, the effect of LTG monotherapy on bone health is controversial and the underlying mechanism through which LTG monotherapy may affect bone remodeling is still unknown. However, it has been suggested that LTG monotherapy may affect 
bone metabolism, inducing the development of parathyroid hormone resistance and compensating for bone loss through increasing bone formation ${ }^{27,31}$.

In our study, both patients on LEV polytherapy (LEV+VPA combination) and those on LTG polytherapy (LTG+VPA combination) showed a negative effect on bone. It has been demonstrated that LTG and/or VPA therapies for more than two years were associated with low bone mineral density, reduced bone formation (reduced plasma osteocalcin) and short stature in children with epilepsy ${ }^{31}$. These previouslymentioned findings reported by Guo et al. ${ }^{32}$ corroborate the results obtained in the current study concerning the effect of antiepileptic polytherapy on bone health. However, a previously-reported cross-sectional study accomplished with different groups of epileptic patients treated with six different AEDs including; carbamazepine, oxcarbazepine, VPA, LTG, topiramate and LEV demonstrated that the patient group treated with AED polytherapies showed nonsignificant changes in bone mineral density ${ }^{16}$.

Long-term antiepileptic treatment with VPA may cause osteopenia in both sexes ${ }^{5,28,33,34,35,36}$. Many authors have noticed a significant reduction of bone marrow density $5,28,32,34,35$. Some studies found results suggesting that serum calcium concentrations may be significantly lower in patients receiving $\mathrm{VPA}^{28,33,34}$. In many studies, serum levels of intact parathyroid hormone were within the normal range $e^{28,30,32,34,35,36}$. Increases in serum levels of total alkaline phosphatase have been reported in several studies ${ }^{28,35,37}$. In two studies, the osteocalcin levels of the patient group were significantly higher than the control group ${ }^{5,27,36}$. Urine values of deoxypyridinoline showed no significant difference between epileptic and healthy children $^{27,38.39}$. All the aforementioned prove that data on the effect of antiepileptic polytherapy on bone health are still conflicting and require further investigation.

In this context, our study aimed to evaluate the effects of new AEDs on bone health. The data obtained in our study revealed that LEV monotherapy showed harmful effects on bone but LTD monotherapy did not. Even though antiepileptic polytherapy has been associated with negative effects on bone, there was no difference between LEV in monotherapy and polytherapy, while LTG polytherapy showed a decrease bone mineral density compared with LTG monotherapy. However, this work needs further expansion through large scale, longitudinal studies with different bone types in order to clarify and understand which AEDs can affect bone health.

\section{References}

1. Shawky RM, Elsayed NS, Ibrahim DS, Seifeldin NS. Profile of genetic disorders prevalent in northeast region of Cairo, Egypt. Egypt J Med Hum Genet. 2012;13(1):45-62. https://doi.org/10.1016/j.ejmhg.2011.10.002

2. Souverein PC, Webb DJ, Petri H, Weil J, Van Staa TP, Egberts T. Incidence of fractures among epilepsy patients: a populationbased retrospective cohort study in the General Practice Research Database. Epilepsia. 2005 Feb;46(2):304-10. https://doi.org/10.1111/j.0013-9580.2005.23804.x

3. Farhat G, Yamout B, Mikati MA, Demirjian S, Sawaya R, El-Hajj Fuleihan G. Effect of antiepileptic drugs on bone density in ambulatory patients. Neurology. 2002 May;58(9):1348-53. https://doi.org/10.1212/WNL.58.9.1348

4. Koch HU, Kraft D, von Herrath D, Schaefer K. Influence of diphenylhydantoin and phenobarbital on intestinal calcium transport in the rat. Epilepsia. 1972 dec;13(6):829-34. https://doi.org/10.1111/j.1528-1157.1972.tb05167.x

5. Sato Y, Kondo I, Ishida S, Motooka H, Takayama K, Tomita Y et al. Decreased bone mass and increased bone turnover with valproate therapy in adults with epilepsy. Neurology. 2001 Aug;57(3):445-9. https://doi.org/10.1212/WNL.57.3.445

6. Fitzpatrick LA. Pathophysiology of bone loss in patients receiving anticonvulsant therapy. Epilepsy Behav. 2004 Feb;5 Suppl 2:S3-15. https://doi.org/10.1016/j.yebeh.2003.11.026

7. Ducy P, Desbois C, Boyce B, Pinero G, Story B, Dunstan C et al. Increased bone formation in osteocalcin-deficient mice. Nature. 1996 Aug;382(6590):448-52. https://doi.org/10.1038/382448a0

8. Eyre D. New biomarkers of bone resorption. J Clin Endocrinol Metab. 1992 Mar;74(3):470A-470C. https://doi.org/10.1210/jcem.74.3.1740477

9. Abou-Khalil B. Benefit-risk assessment of levetiracetam in the treatment of partial seizures. Drug Saf. 2005;28(10):871-90. https://doi.org/10.2165/00002018-200528100-00004
10. Zhang J, Wang KX, Wei Y, Xu MH, Su JM, Bao YG et al. [Effect of topiramate and carbamazepine on bone metabolism in children with epilepsy]. Zhongguo Dang Dai Er Ke Za Zhi. 2010 Feb;12(2):96-8. Chinese.

11. Nissen-Meyer LS, Svalheim S, Taubøll E, Reppe S, Lekva T, Solberg LB et al. Levetiracetam, Phenytoin, and valoproate act differently on rat bone mass, structure, and metabolism. Epilepsia. 2007;48(10):1850-60. https://doi.org/10.1111/j.1528-1167.2007.01176.x

12. Block G, Hartman AM, Dresser CM, Carroll MD, Gannon J, Gardner L. A data-based approach to diet questionnaire design and testing. Am J Epidemiol. 1986 Sep;124(3):453-69. https://doi.org/10.1093/oxfordjournals.aje.a114416

13. Katzman DK, Bachrach LK, Carter DR, Marcus R. Clinical and anthropometric correlates of bone mineral acquisition in healthy adolescent girls. J Clin Endocrinol Metab. 1991 Dec;73(6):1332-9. https://doi.org/10.1210/jcem-73-6-1332

14. Lee JW, Dworetzky B. Rational Polytherapy with Antiepileptic Drugs. Pharmaceuticals (Basel). 2010 Jul;3(8):2362-79. https://doi.org/10.3390/ph3082362

15. Delmas PD, Eastell R, Garnero P, Seibel MJ, Stepan J; Committee of Scientific Advisors of the International Osteoporosis Foundation]. The use of biochemical markers of bone turnover in osteoporosis. Osteoporos Int. 2000;11(0 Suppl 6):S2-17. https://doi.org/10.1007/s001980070002

16. Beniczky SA, Viken J, Jensen LT, Andersen NB. Bone mineral density in adult patients treated with various antiepileptic drugs. Seizure. 2012 Jul;21 (6):471-2. https://doi.org/10.1016/j.seizure.2012.04.002

17. Fekete S, Simko J, Gradosova I, Malakova J, Zivna H, Palicka V et al. The effect of levetiracetam on rat bone mass, structure and metabolism. Epilepsy Res. 2013 Nov;107(1-2):56-60. https://doi.org/10.1016/j.eplepsyres.2013.08.012

18. Anwar MJ, Radhakrishna KV, Vohora D. Phenytoin and sodium valproate but not levetiracetam induce bone alterations in female mice. Can J Physiol Pharmacol. 2014 Jun;92(6):507-11. https://doi.org/10.1139/cjpp-2013-0504 
19. Lee R, Lyles K, Sloane R, Colón-Emeric C. The association of newer anticonvulsant medications and bone mineral density. Endocr Pract. 2012 Sep;1-22. https://doi.org/10.4158/EP12119.OR

20. Nordahl J, Hollberg K, Mengarelli-Widholm S, Andersson G, Reinholt FP. Morphological and functional features of clasts in low phosphate, vitamin D-deficiency rickets. Calcif Tissue Int. 2000 Nov;67(5):400-7. https://doi.org/10.1007/s002230001151

21. Carretero RG, Brugera MR, Olid-Velilla M, Salamanca-Ramirez I. Pancytopenia associated with levetiracetam in an epileptic woman. BMJ Case Reports. 2016. https://doi.org/10.1136/bcr-2016-217407

22. Alzahrani T, Kay D, Alqahtani SA, Makke Y, Lesky L, Koubeissi MZ. Levetiracetam-induced pancytopenia. Epilepsy Behav Case Rep. 2015;4:45-7. https://doi.org/10.1016/j.ebcr.2015.06.001

23. Aydoğan H, Yalçn S, Karahan MA, Büyükfrat E. Pancytopenia associated with levetiracetam treatment in Lafora's disease. Blood Coagul Fibrinolysis. 2012 Mar;23(2):175. https://doi.org/10.1097/MBC.0b013e32834bdb5f

24. Gallerani M, Mari E, Boari B, Carletti R, Marra A, Cavallo M. Pancytopenia associated with levetiracetam treatment. Clin Drug Investig. 2009;29(11):747-51. https://doi.org/10.2165/11319450-000000000-00000

25. Rosca EC, Simu M. Levetiracetam-induced hyponatremia. Acta Neurol Belg. 2018 Mar;118(1):123-4. https://doi.org/10.1007/s13760-017-0825-4

26. Kimland E, Höjeberg M, Euler M. Levetiracetam-induced Thrombocytopenia case. Epilepsia. 2004;45(7):877-8.

27. Kim SH, Lee JW, Choi KG, Chung HW, Lee HW. A 6-month longitudinal study of bone mineral density with antiepileptic drug monotherapy. Epilepsy Behav. 2007 Mar;10(2):291-5. https://doi.org/10.1016/j.yebeh.2006.11.007

28. Pack AM, Morrell MJ, Marcus R, Holloway L, Flaster E, Doñe $S$ et al. Bone mass and turnover in women with epilepsy on antiepileptic drug monotherapy. Ann Neurol. 2005 Feb;57(2):252-7. https://doi.org/10.1002/ana.20378

29. Stephen LJ, McLellan AR, Harrison JH, Shapiro D, Dominiczak $\mathrm{MH}$, Sills GJ et al. Bone density and antiepileptic drugs: a case-controlled study. Seizure. 1999 Sep;8(6):339-42. https://doi.org/10.1053/seiz.1999.0301
30. Sheth RD, Hermann BP. Bone mineral density with lamotrigine monotherapy for epilepsy. Pediatr Neurol. 2007 Oct;37(4):250-4. https://doi.org/10.1016/j.pediatrneurol.2007.05.018

31. Simko J, Fekete S, Gradosova I, Malakova J, Zivna H, Valis M et al. The effect of topiramate and lamotrigine on rat bone mass, structure and metabolism. J Neurol Sci. 2014 May;340(1-2):80-5. https://doi.org/10.1016/j.jns.2014.02.032

32. Guo CY, Ronen GM, Atkinson SA. Long-term valproate and lamotrigine treatment may be a marker for reduced growth and bone mass in children with epilepsy. Epilepsia. 2001 Sep;42(9):1141-7. https://doi.org/10.1046/j.1528-1157.2001.416800.x

33. Tsukahara H, Kimura K, Todoroki Y, Ohshima Y, Hiraoka M, Shigematsu $Y$ et al. Bone mineral status in ambulatory pediatric patients on long-term anti-epileptic drug therapy. Pediatr Int. 2002 Jun;44(3):247-53. https://doi.org/10.1046/j.1442-200X.2002.01561.x

34. Kumandas S, Koklu E, Gümüs H, Koklu S, Kurtoglu S, Karakukcu M et al. Effect of carbamezapine and valproic acid on bone mineral density, IGF-I and IGFBP-3.J Pediatr Endocrinol Metab. 2006 Apr;19(4):529-34.

35. Babayigit A, Dirik E, Bober E, Cakmakci H. Adverse effects of antiepileptic drugs on bone mineral density. Pediatr Neurol. 2006 Sep;35(3):177-81. https://doi.org/10.1016/j.pediatrneurol.2006.03.004

36. Oner N, Kaya M, Karasalihoğlu S, Karaca H, Celtik C, Tütüncüler F. Bone mineral metabolism changes in epileptic children receiving valproic acid. J Paediatr Child Health. 2004 Aug;40(8):470-3. https://doi.org/10.1111/j.1440-1754.2004.00431.x

37. Bouillon R, Reynaert J, Claes JH, Lissens W, De Moor P. The effect of anticonvulsant therapy on serum levels of 25-hydroxy-vitamin D, calcium, and parathyroid hormone. J Clin Endocrinol Metab. 1975 Dec;41(06):1130-5. https://doi.org/10.1210/jcem-41-6-1130

38. Rieger-Wettengl G, Tutlewski B, Stabrey A, Rauch F, Herkenrath P, Schauseil-Zipf $U$ et al. Analysis of the musculoskeletal system in children and adolescents receiving anticonvulsant monotherapy with valproic acid or carbamazepine. Pediatrics. 2001 Dec;108(6):E107. https://doi.org/10.1542/peds.108.6.e107

39. Song XQ, Wang ZP, Bao KR, Zhang JM, Wu J, Yan CH et al. [Effect of carbamazepine and valproate on bone metabolism in children with epilepsy]. Zhonghua Er Ke Za Zhi. 2005 Oct;43(10):728-32. Chinese. 